\title{
Influence of Carbides Morphology on Fracture Toughness of Cast Steel G200CrMoNi4-3-3
}

\author{
Z. Stradomski, ${ }^{1, \mathrm{a}}$ A. Pirek, ${ }^{1, \mathrm{~b}}$ and D. Dyja ${ }^{1, \mathrm{c}}$ \\ ${ }^{1}$ Czestochowa University of Technology, Institute of Materials Engineering, Czestochowa, Poland

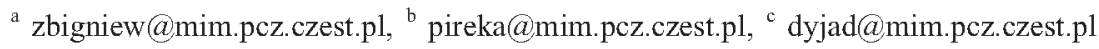

We analyze the influence of small modification of chemical composition of G200CrMoNi4-3-3 cast steel on the morphology of carbides and on material crack resistance. Using the Termo-Calc software the volume fraction of carbide phase was determined and the results correlated with microstructure observations. Crack resistance of cast steel was determined using SENB specimens and finding critical values of stress intensity factor $K_{Q}$. Metallographic and fractographic observations of fracture surfaces allowed identifying the mechanism of cracking.

Keywords: fracture toughness, hardness, carbides, rolls.

Introduction. A specific and separate group of tool materials is represented by steels and cast steels for mill rolls. Hypereutectoid steels are largely represented in this group, in which the abrasion resistance is guaranteed by large carbide precipitates according to the following Zum Gahr equation [1]:

$$
W=\frac{d^{3 / 2} V_{V}}{\lambda},
$$

where $d$ is size of carbides, $V_{V}$ is volume fracture, $\lambda$ is mean free path, and $W$ is wear resistance.

Substantial initial diameters of rolls as well as the need of machining related to the surface wear or changes in the pass geometry make that the heat treatment of those cast steels is very limited. It is reduced most often to normalizing and stress-relief annealing. However, not too hard pearlitic matrix under conditions of dry friction shows very good resistance to abrasive wear, what is indicated by literature data [1-3] and own authors' research $[4,5]$.

Cast steels containing substantial amounts of carbon have a drawback consisting in the presence of large carbide precipitates, which create more or less continuous network of ledeburite and hypereutectoid cementite. Such microstructure, though favorable from the point of view of tribological properties, strongly reduces the material crack resistance $[3,6]$.

Taking into consideration the above aspects of microstructure, we have used parameters of fracture mechanics to optimize the structure of G200CrMoNi4-3-3 cast steel. The paper has been focused on determination of the influence of small modification of chemical composition of G200CrMoNi4-3-3 cast steel on the morphology of carbides and the material crack resistance.

Materials and Methodology. High-carbon low-alloy cast steel has been used in the investigation, in which diversified carbides content was obtained through small modification of chemical composition resulting, however, in substantial increased in volume fraction of carbide phase. The material for studies was taken from upper neck of mill rolls weighing around $10000 \mathrm{~kg}$. The chemical composition (in mass \%) of studied G200CrMoNi4-3-3 cast steels was specified in Table 1.

Residual stresses and the character of microstructure were analyzed after the as-cast rolls have been subjected to long-term heat treatment (about $160 \mathrm{~h}$ ) consisting of normalizing and tempering at a temperature below $A_{C_{1}}$. Based on the chemical composition 
of examined heats the transformation temperatures of eutectic $\left(E^{\prime}, C^{\prime}\right)$ and eutectoid $\left(S^{\prime}\right)$ transformation have been determined using the Termo-Calc computer software. Volume fractions of primary carbides $V_{V \text { ledeburite }}$ and of hypereutectoid cementite $V_{V \mathrm{Fe}_{3} \mathrm{C}}$ have been determined, taking into account also the normalizing temperature (point in $A_{C_{m}}$ line).

$\mathrm{T}$ a b 1 e 1

Chemical Composition of the Cast Steels

\begin{tabular}{|c|c|c|c|c|c|c|c|c|c|}
\hline Rolls & $\mathrm{C}$ & $\mathrm{Mn}$ & $\mathrm{Si}$ & $\mathrm{P}$ & $\mathrm{S}$ & $\mathrm{Cr}$ & $\mathrm{Ni}$ & $\mathrm{Mo}$ & $\mathrm{Cu}$ \\
\hline 1 & 1.89 & 0.58 & 0.42 & 0.028 & 0.007 & 1.15 & 0.58 & 0.37 & 0.09 \\
\hline 2 & 2.10 & 0.54 & 0.58 & 0.038 & 0.010 & 1.59 & 0.48 & 0.52 & 0.11 \\
\hline 3 & 2.12 & 0.72 & 0.55 & 0.017 & 0.005 & 1.13 & 0.74 & 0.38 & 0.12 \\
\hline 4 & 2.16 & 0.67 & 0.56 & 0.025 & 0.016 & 1.07 & 0.62 & 0.39 & 0.14 \\
\hline 5 & 2.20 & 0.59 & 0.53 & 0.019 & 0.006 & 1.11 & 0.65 & 0.40 & 0.11 \\
\hline 6 & 2.22 & 0.74 & 0.61 & 0.026 & 0.010 & 1.06 & 0.64 & 0.37 & 0.12 \\
\hline
\end{tabular}

Results. The influence of carbide-forming elements on the position of transformation temperatures and carbides volume fractions is specified in Table 2. The obtained results have been confirmed by microstructural analysis of selected rolls. Some of micrographs are presented in Fig. 1.

$\mathrm{T}$ a b 1 e 2

The Influence of Carbide-Forming Elements on the Position of Transformation Temperatures of $\mathrm{Fe}^{-} \mathrm{Fe}_{3} \mathrm{C}$ System and Carbides Volume Fractions

\begin{tabular}{|c|c|c|c|c|c|c|c|c|c|}
\hline \multirow{2}{*}{ Rolls } & \multicolumn{3}{|c|}{$\begin{array}{c}\text { Chemical } \\
\text { compositions }\end{array}$} & \multicolumn{3}{c|}{ Point of Fe-C } & $V_{V}$ & $V_{V}$ & $\sum V_{V}$ \\
\cline { 2 - 11 } & $\mathrm{C}$ & $\mathrm{Cr}$ & $\mathrm{Mo}$ & $E^{\prime}$ & $C^{\prime}$ & $S^{\prime}$ & ledeburite & $\mathrm{Fe}_{3} \mathrm{C}$ & ledeburite $+\mathrm{Fe}_{3} \mathrm{C}$ \\
\cline { 2 - 11 } & \multicolumn{3}{|c|}{$\%$} & \multicolumn{3}{|c|}{$\% \mathrm{C}$} & \multicolumn{2}{|c|}{$\%$} & $\%$ \\
\hline 1 & 1.89 & 1.15 & 0.37 & 2.021 & 4.3745 & 1.38 & 0 & 10.90 & 10.9 \\
\hline 2 & 2.10 & 1.43 & 0.52 & 2.006 & 4.3725 & 1.34 & 4.14 & 16.63 & 20.8 \\
\hline 3 & 2.12 & 1.13 & 0.38 & 2.020 & 4.3750 & 1.34 & 4.43 & 17.14 & 21.6 \\
\hline 4 & 2.16 & 1.07 & 0.39 & 2.019 & 4.3749 & 1.34 & 6.36 & 18.18 & 24.5 \\
\hline 5 & 2.20 & 1.11 & 0.40 & 2.018 & 4.3746 & 1.34 & 8.36 & 19.24 & 27.6 \\
\hline 6 & 2.22 & 1.06 & 0.37 & 2.021 & 4.3752 & 1.34 & 9.23 & 19.78 & 29.0 \\
\hline
\end{tabular}
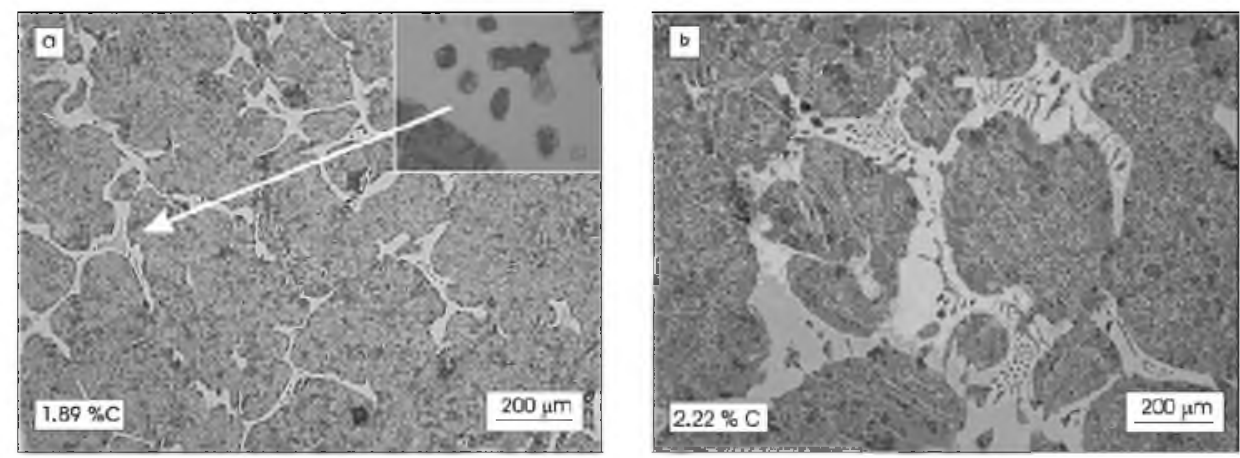

Fig. 1. Microstructure of the G200CrMoNi4-6-3 cast steel. 
Precipitations of transformed ledeburite in the cast steel of heat 1, shown in Fig. 1a, in which according to Table 2 the eutectic reaction should not occur, result from segregation processes ensued by solidification of massive castings.

The fraction of cementite eutectic, lowered by precipitations of hypereutectoid cementite, increases from the value of 11 to $29 \%$ in cast steel 5 containing $2.22 \% \mathrm{C}$ $1.06 \% \mathrm{Cr}$, and $0.37 \%$ Mo (Fig. 1). Very small changes in carbide-forming elements contents have a significant influence on carbides amount and morphology. As compared to the as-cast state, the normalizing causes dissolution of part of thick network of hypereutectoid cementite, also in a Widmannstatten microstructure.

Hardness was measured by the Brinell method according to the PN-EN ISO 6506-1:2002 standard under a load of $7355 \mathrm{~N}$ with a steel ball of a diameter of $5 \mathrm{~mm}$. The results are specified in Fig. 2.

With increasing volume fraction of carbide phase (ledeburite and hypereutectoid cementite precipitated in the form of more or less continuous network) the propensity for brittle fracture propagation increases in the structure. The crack resistance of cast steel with diversified content of carbide phase was evaluated based on the stress intensity factor $K_{O}$, determined in accordance with ASTM E399-90 recommendations. SENB specimens, with dimensions $80 \times 10 \times 20 \mathrm{~mm}$ and mechanically cut $10 \mathrm{~mm}$ depth notch, were tested by three-point bending. Results of tests carried out on an MTS-810 testing machine are presented in Fig. 3.

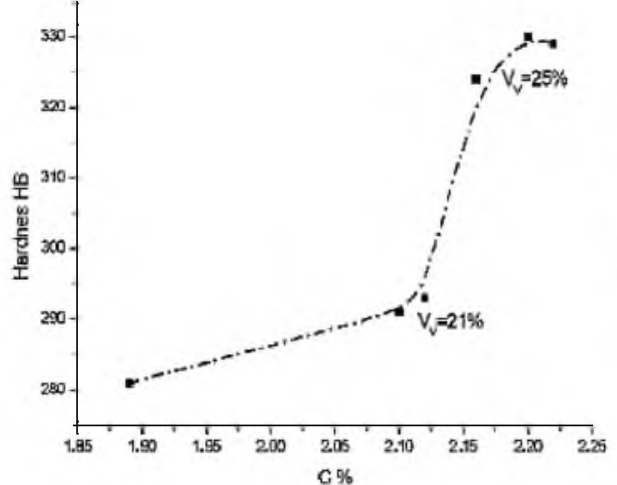

Fig. 2

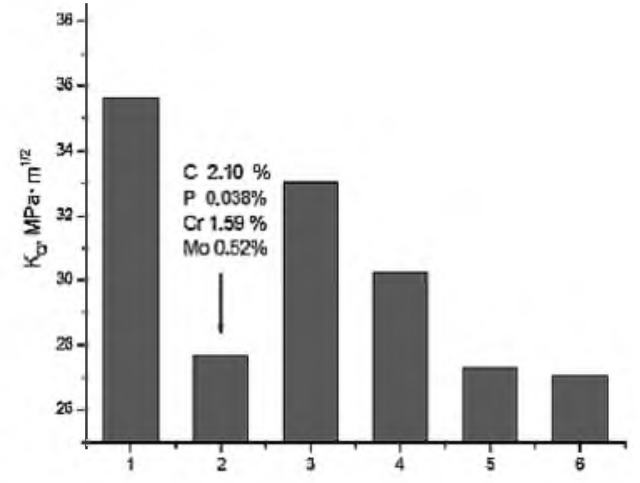

Fig. 3

Fig. 2. Influence of the carbon content on the hardness.

Fig. 3. Influence of the chemical composition on the fracture toughness.

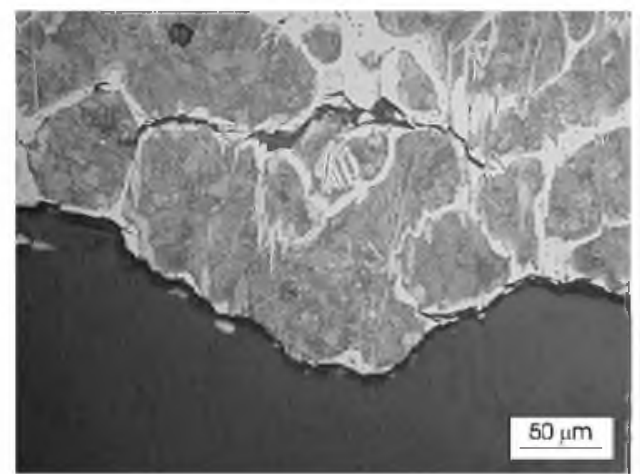

Fig. 4

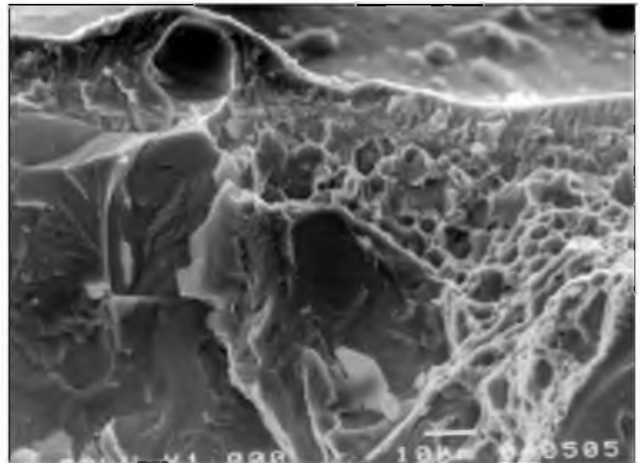

Fig. 5

Fig. 4. Microstructure of the cast steel below notch in SENB specimens.

Fig. 5. SEM microphotographs of the cast steel. 
Approximately $200 \%$ growth in the carbide phase amount, precipitated mainly at primary boundaries of austenite grains, is accompanied by around $25 \%$ decrease in $K_{Q}$ value. Strong decline in $K_{Q}$ of roll 2 results from substantial amount of phosphorus precipitated in the form of brittle phosphorus eutectic, revealed both by microscopic and fractographic examinations.

The mechanism of cracking was analyzed using a scanning and optical microscope on metallographic microsections taken from regions below the specimens notch root. The results of observations show that the fracture proceeds along the network of transformed ledeburite and precipitations of hypereutectoid cementite (Fig. 4), while it goes through the pearlitic matrix only in short sections.

Fractographic examinations (Fig. 5) confirm observations of the material microstructure. The material is cracking both along grain boundaries 'decorated' with carbides, what is frequently accompanied by brittle fracture, as well as through pearlite grains, cracking in a ductile mode. Ductile mechanism of pearlite cracking is caused mainly by fine globular precipitations of secondary carbides.

\section{Conclusions}

1. Increase in carbon content from $1.89 \%$ to $2.22 \%$ caused a two-times increase in the volume fraction of ledeburite and hypereutectoid cementite, precipitated in the form of more or less continuous network.

2. Two-times increase in the content of carbide phase precipitated in the form of network resulted in around $20 \%$ increase in hardness, parallel to crack resistance decreased by $25 \%$.

3. Low value of stress intensity factor $K_{Q}$ for heat 2 resulted from the presence of phosphorus eutectic in the alloy misrostructure.

4. The higher than recommended phosphorus content, in particular in high-carbon cast steels, results in substantial increase in their brittleness and may cause a premature damage to the roll.

1. K. H. Zum Gahr, "Microstructure and wear of materials," in: Tribology, Series 10, Elsevier, Amsterdam (1987), pp. 227-252.

2. Y. S. Liao and R. H. Shiue, "Effect of carbide orientation on abrasion of high $\mathrm{Cr}$ white cast iron," Wear, 193, 16-24 (1996).

3. You Wang, Tingquan Lei, and Jiajun Liu, "Tribo-metallographic behavior of high carbon steels in sliding," Wear, 231, 1-11 (1999)

4. Z. Stradomski and S. Stachura, "Role of microstructure in the mechanism of abrasive wear of high-carbon steel," Acta Metall. Slovaca, R. 8, No. 2/2, 388-393 (2002).

5. Z. Stradomski, S. Stachura, A. Pirek, and P. Chmielowiec, "The affect of the amout of primary carbides on the wear resistance of the G200CrMoNi4-6-3 (L200 HNM) cast steel," Inzynieria Materialowa, No. 3, XX-XXIII (2004).

6. S. C. Lim, M. F. Ashby, and J. H. Brunton, "Wear-rate transitions and their relationship to wear mechanisms," Acta Metall., 35, No. 6, 1343-1348 (1991).

Received 28. 06. 2007 